\title{
On Regional Public Security Threshold Effect -Exploration Based on Vulnerability-Ability Analysis Framework
}

\author{
Wang Wei ${ }^{1}$, Liu Zezhao ${ }^{2,3}$ \\ (1. School of Public Policy \& Management, Xi`an Jiaotong University, Xi`an, P.R. China, 710049 \\ 2. School of Management, Xi`an Jiaotong University, Xi an, P.R. China, 710049 \\ 3. Shaanxi Emergency Management Academy, Xi`an, P.R. China, 710072) \\ (Email: xjturabbit@sina.cn; ecsi@163.com)
}

\begin{abstract}
By the "vulnerability-ability" framework, the paper carries a systematic analysis of the threshold value of regional public security through the collection of 2003-2010 provincial data calculated. Based on the objective data evaluation and fuzzy comprehensive evaluation algorithm, the research makes the results more true and effective. Following the analysis of threshold value, this paper furthermore takes an analysis on the mechanism principle, points out the differences and relations for vulnerability and ability in the system to achieve threshold before and after. It also verifies the reliability of the threshold and expounds the position and function of threshold value in regional complex system of public security.
\end{abstract}

Key words: vulnerability-ability; public security; threshold value

\section{Introduction}

In recent years, threshold value is wildly applied in a wide range of fields as information science, meteorology, medicine, but the state public security threshold value is little concerned due to diversified values and social context [1]. To some extent the threshold value of regional public security plays a significant and practical role in analytical system research. Just as Luers (2005) highlights that "whatever the generalized form of vulnerability measure, there is an inescapable need for a threshold of risk, danger or harm"[2].

Threshold (some scholars also called "critical value"), is a field or system boundary. Breaking through threshold, it often stands for state evolution transition. Marxist dialectical materialism pointed out that "a qualitative change always gets the corresponding amount of quantity change" [3]. Quantity influencing quality from the objective law of the philosophical level well explains the natural and social development process of the threshold value in common. French scientist creates a mutation system theory (R. Thom, 1972) and further specifies threshold as "singularities of smooth mappings, stratified spaces, singularities of differential forms, bifurcation theory, and qualitative dynamics"[4]. The threshold for regional public safety is of special significance, and some of the existing research expand our horizons, for instance, Niemeyer et al. (2005) introduce the psychology of the Q method of members in society to climate warming reaction, clarifying the existence and effects of the threshold in social risks related [5]. Lagi et al. (2011) use the empirical data to analyze relations between food prices and social unrest, the findings of which show that when a region of the FAO price index reached 210, the region is easy to fall into social unrest. [6]

High-frequency occurrence of emergencies has been treated as one of the characteristics of modern society, meanwhile the inherent complexity comprised in public crisis has attracted many researchers in taking on 
everlasting exploration, building different research perspectives to establish synthetic public security evaluation model. The international community has formed a series of a mature public security assessment framework, generally experienced from the pure "vulnerability" angle (the United Nations Development Program DRI index system for representative[7]) or "capacity" angle (the United States COOP evaluation scale for representative[8]) and then to "vulnerability-capacity" comprehensive angle[9]). Based on the theory and practice perspective of vulnerability - capacity of regional public safety at home and abroad, Zhu (2011) put forward a comprehensive evaluation framework. [10] In theoretical research and practical development process, vulnerability and capacity for regional public safety evolutionary direction have the opposite effects. In short, when a regional system is weak, vulnerability and regional public security situation deteriorated, potential probability of public crisis increases. If the regional public safety risk overtakes the greatest risk boundary, the system is likely to mutate under specific external perturbations leading the crisis publicly exposed, thus the formation of the system is in the state of hazards.

\section{Procedure and Technical Design}

\subsection{Threshold system analysis and index options selection}

Regional public security system is a complex system influenced by more factors, and in public security level (public security risk index for representative) affected mutually from aspects of "vulnerability" and "coping capacity". Because the system containing vulnerability \& capacity factors is reflected in different aspects, and in the extension of time \& space the influence within is not identical, therefore, in the reality vulnerability and capacity factors do not determine public security level through the simple act of positive and negative way, but manifest complex evolution mechanism of public security system, and both together with threshold effect reflect regional public security posture. When a regional public safety risk index exceeds the threshold, the role of potential disturbance will cause the system to mutations, and thus lead to public crisis.

Based on the report Living with Risk: A global review of disaster reduction initiatives (2004) compiled by United Nations Inter-Agency Secretariat of the International Strategy for Disaster Reduction (UN/ISDR) ${ }^{[11]}$, this article puts regional public security vulnerability into resource vulnerability, social vulnerability, economic vulnerability, and environmental vulnerability, meanwhile handles coping capacity into public service, social prevention, financial support, and environmental monitoring. Afterwards, according to the measurable, effective and reliable principle, we determine the risk assessment index system of comprehensive classification (as see table 1).

\subsection{Assessment method and implementation}

\subsubsection{Data acquisition and processing}

This article selects 31 provincial administrative areas in China as the evaluation object. By statistical yearbook published in China, statistical regional bulletins over the national economic and social development, related special research reports, we collect relevant 2003-2010 data in the region. To remove many differences of numerical and dimensional distortion of the data, firstly we in a certain principle collect data for the dimensionless processing.

Detail calculation process is as follows:

positive index:

$$
y_{i j}=\frac{x_{i j}-x_{j \min }}{x_{j \max }-x_{j \min }}
$$

\begin{tabular}{c|c|c}
\hline Field & Scope & Measurable index \\
\hline \multirow{3}{*}{$\begin{array}{c}\text { Vulnerability } \\
\text { (V) }\end{array}$} & Vulnerability of Resource & cultivated land area per capita, water resources per capita, \\
& population density, power consumed per capita \\
\cline { 2 - 3 } & Vulnerability of Society & rural unemployment, unban/rural consumption ratio, numbers of \\
& tVS $)$ & traffic accidents and fires
\end{tabular}




\begin{tabular}{|c|c|c|}
\hline & $\begin{array}{l}\text { Vulnerability of Economy } \\
\qquad \text { (VE) }\end{array}$ & $\begin{array}{l}\text { CPI, Urban and rural residents income level, GDP per capita, } \\
\text { Engel's coefficient, compensation of employees rate, tertiary } \\
\text { industry rate }\end{array}$ \\
\hline & $\begin{array}{l}\text { Vulnerability of Circumstance } \\
\qquad(\mathrm{VC})\end{array}$ & $\begin{array}{l}\text { number of environmental accidents, industrial solid wastes } \\
\text { produced, waste water discharge, industrial waste gas emission, } \\
\text { affected agricultural area, destructed forest area }\end{array}$ \\
\hline \multirow{4}{*}{$\begin{array}{l}\text { Coping Capacity } \\
\text { (C) }\end{array}$} & $\begin{array}{l}\text { Capacity of Public Service } \\
\text { (CPS) }\end{array}$ & $\begin{array}{l}\text { beds in health care institutions per } 1000 \text { persons, medical technical } \\
\text { personnel per } 1000 \text { persons, number of community services } \\
\text { facilities, density of transport routes }\end{array}$ \\
\hline & $\begin{array}{l}\text { Capacity of Social Prevention } \\
\qquad \text { (CSP) }\end{array}$ & $\begin{array}{l}\text { coverage scale of basic medical care insurance, urban basic } \\
\text { pension insurance, and unemployment insurance }\end{array}$ \\
\hline & $\begin{array}{l}\text { Capacity of Financial Support } \\
\qquad(\mathrm{CFS})\end{array}$ & $\begin{array}{l}\text { public security budget proportion, public security budget for } \\
\text { average, ordinary public services budget proportion, ordinary } \\
\text { public services budget for average }\end{array}$ \\
\hline & $\begin{array}{l}\text { Capacity of Environmental } \\
\text { Monitoring } \\
\text { (CER) }\end{array}$ & $\begin{array}{l}\text { utilization rate of industrial solid wastes, waste water meeting } \\
\text { discharge standards rate, rate of industrial waste gas removed, } \\
\text { treatment rate of consumption wastes, prevention rate of forest } \\
\text { diseases, investment of prevention of geological disasters }\end{array}$ \\
\hline
\end{tabular}

Tab.1. Regional social security assessment index

Negative index:

$$
y_{i j}=\frac{x_{j \max }-x_{i j}}{x_{j \max }-x_{j \min }}
$$

Index weight coefficient represents the relative importance of index. In this article, the quantitative data are used in the standard deviation method to determine the weights of the index coefficient, which regards the

Mean of index item $j E\left(I_{j}\right)$ :

$$
E\left(I_{j}\right)=\frac{1}{n} \sum_{i=1}^{n} y_{i j}
$$

Mean deviation of index item $j \sigma\left(I_{j}\right)$ :

$$
\sigma\left(I_{j}\right)=\left[\sum_{i=1}^{n}\left(y_{i j}-E\left(I_{j}\right)\right)^{2}\right]^{\frac{1}{2}}
$$

Weigh coefficient of index item $j \omega_{j}$ :

$$
\omega_{j}=\sigma\left(I_{j}\right) / \sum_{j=1}^{m} \sigma\left(I_{j}\right)
$$

\subsubsection{Fuzzy comprehensive assessment}

By 31 provincial administrative regions, we set up evaluation index factor set $U=\left\{\mathrm{u}_{1}, \mathrm{u}_{2}, \cdots, \mathrm{u}_{\mathrm{m}}\right\}$, assessment set $\mathrm{V}=\left\{\mathrm{v}_{1}, \mathrm{v}_{2}, \cdots, \mathrm{v}_{\mathrm{p}}\right\}$. Determine the fuzzy weight vector of the factors set:

$$
\underset{\sim}{A}=\frac{a_{1}}{u_{1}}+\frac{a_{2}}{u_{2}}+\cdots+\frac{a_{m}}{u_{m}} \quad\left(0 \leqslant a_{i} \leqslant 1\right)
$$


Establish fuzzy comprehensive evaluation matrix between the factors sets universe and evaluation sets universe:

Fuzzy assessment results:

$$
\underset{\sim}{R}=\left[\begin{array}{cccc}
r_{11} & r_{12} & \cdots & r_{1 p} \\
r_{21} & r_{22} & \cdots & r_{2 p} \\
\cdots & \cdots & \cdots & \cdots \\
r_{m 1} & r_{m 2} & \cdots & r_{m p}
\end{array}\right]
$$

\subsubsection{Threshold judgment}

Based on the measure principle above, we explore the feasible judgment of the threshold method, which is to compare the risk index measured with direct practical economic losses. In order to overcome some of the great disaster random disturbance, this article analyzed various kinds of public security incident; especially take the kinds of typical public security incident that can effectively rule out of outside interference. We use direct economic losses in proportion of GDP of typical public

$$
\frac{\left|x_{i}-E\left(x_{i}\right)\right|}{\sqrt{\sum_{i=1}^{n}\left(x_{i}-E\left(x_{i}\right)\right)^{2}}} \geqslant 2
$$

In the years from 2003 to 2010, the abnormal risk index points of public security actual loss all exceed 0.5 . Further we divide risk index into two groups (the first group is the risk index set less $\mathrm{t}$

\begin{tabular}{ll}
\hline Year & \multicolumn{1}{c}{ Abnormal values (area number, risk index $)$} \\
\hline 2010 & $(\mathrm{~S} 23,0.5630)(\mathrm{S} 24,0.5314)(\mathrm{S} 25,0.5714)(\mathrm{S} 28,0.5508)$ \\
2009 & $(\mathrm{~S} 25,0.6212)$ \\
2008 & $(\mathrm{~S} 22,0.5192)(\mathrm{S} 25,0.5629)(\mathrm{S} 28,0.5965)$ \\
2007 & $(\mathrm{~S} 22,0.5341)(\mathrm{S} 23,0.6329)(\mathrm{S} 25,0.6371)(\mathrm{S} 29,0.5090)$ \\
2006 & $(\mathrm{~S} 13,0.5321)(\mathrm{S} 17,0.5262)(\mathrm{S} 18,0.5635)(\mathrm{S} 28,0.5345)$ \\
2005 & $(\mathrm{~S} 12,0.5587)(\mathrm{S} 13,0.5117)(\mathrm{S} 23,0.5726)(\mathrm{S} 25,0.5565)$ \\
2004 & $(\mathrm{~S} 22,0.5284)(\mathrm{S} 25,0.6450)$ \\
2003 & $(\mathrm{~S} 18,0.5876)(\mathrm{S} 24,0.5716)(\mathrm{S} 27,0.5325)$ \\
\hline
\end{tabular}

Tab.2. Abnormal value for regional public security level

0.5 , while the second one is equal to or greater than 0.5). We take ANOVA analysis, and get F-value as $17.762(\mathrm{p}<0.001)$, and confirm that the actual loss has differences before and after threshold. Namely, when risk index exceed the levels of 0.5 , regional public security system would transit from a stable state into an unsteady one, under the disturbance and the influence of system outside, there is greater probability of mutations; When risk index is less than 0.5 level, the system would be in a steady state. Based on the research above, our preliminary judgment is that the threshold level of regional public security risk index locates at 0.5 around; the following process will furthermore test the conclusion. 


\section{Test analysis}

Both vulnerability and capacity affect the state of regional public security, while differences do exist between the two kinds of factors ${ }^{[12]}$. When vulnerability is inferior to the boundaries of system's coping ranges, that is, the risk index does not exceed the threshold value, both vulnerability and capacity have great influences on public security. If vulnerability breakthrough the boundaries, i.e., system's risk index exceeds its threshold, capacity factors will be more constrained.

\begin{tabular}{cccccccc}
\hline \multirow{2}{*}{ Year } & \multicolumn{3}{c}{ W1 } & \multicolumn{3}{c}{ W2 } & \multicolumn{3}{c}{ W3 } \\
\cline { 2 - 8 } & V-R & C-R & V-C & V-R & C-R & V-R & C-R \\
\hline 2010 & 0.867 & -0.844 & -0.470 & 0.827 & -0.833 & 0.872 & -0.429 \\
2009 & 0.805 & -0.822 & -0.329 & 0.721 & -0.839 & 0.679 & -0.424 \\
2008 & 0.838 & -0.854 & -0.436 & 0.755 & -0.873 & 0.688 & -0.416 \\
2007 & 0.874 & -0.839 & -0.472 & 0.832 & -0.902 & 0.794 & -0.391 \\
2006 & 0.864 & -0.870 & -0.505 & 0.773 & -0.883 & 0.821 & -0.411 \\
2005 & 0.852 & -0.852 & -0.456 & 0.739 & -0.841 & 0.803 & -0.307 \\
2004 & 0.800 & -0.830 & -0.333 & 0.668 & -0.852 & 0.757 & -0.360 \\
2003 & 0.792 & -0.856 & -0.364 & 0.714 & -0.815 & 0.782 & -0.464 \\
\hline
\end{tabular}

Tab.3. Pearson coefficients among vulnerability, capacity and risk index
In order to test the threshold value forward, we set up three data sets: the first set is the original data set (labeled as W1); the second set is for risk index under 0.5 (labeled as W2); and the third is for risk index exceeding 0.5 (labeled as W3). We explore the commons and differences of the vulnerability and capacity with risk index among the three sets. SPSS 16.0 is used to perform the statistical analysis (results shown as below). a. From the statistical results shown in table 3, the correlation coefficients between vulnerability and risk index among W1, W2, $\mathrm{W} 3$ are positive, and absolute values are all higher than 0.6, instructing both highly relevant. Further we use ANAVA analysis to check the variance of V-R correlation coefficients between $\mathrm{W} 2$ and $\mathrm{W} 3$, with the output $\mathrm{p}$-value $0.504(p>0.1)$, therefore we believe vulnerability values of W2 and W3 are in the obvious indifferences, namely the vulnerability is basically the same as the system is to achieve threshold before and after.

b. We use the same method to make statistical analysis, and the results indicate that the related coefficients between capability value and risk index in $\mathrm{W} 1 \mathrm{~W} 2 \mathrm{~W} 3$ are negative, absolute values $\mathrm{W} 1 \mathrm{~W} 2>0.8$, and the $\mathrm{W} 3$ coefficients focus on interval $(0.3,0.5)$, instructing totally capacity have significant negative relationship with risk level. When the system is to achieve threshold before, the coping capacity manifests high negative correlated with regional public risk level, but when system overtakes threshold, the negative correlation significantly reduced to strength of medium weak.

c. In addition, correlation coefficient between vulnerability and capacity value is negative in W1, and absolute value mainly concentrated in interval $(0.3,0.5)$, instructing the total vulnerability and ability are on a negative correlation. The related degree of capability and risk index remains slightly higher than the vulnerability and risk index In W2, while in W3 related degree between vulnerability and risk index is significantly higher than the ability and the risk index.

\section{Conclusions}

There are significant differences over the relationship between vulnerability \& capacity, and public security level as the system is to achieve threshold before and after. Regarding on vulnerability, the correlation is not significant, while on ability the correlation turns out significant differences When the 
system have not yet reached the threshold value, vulnerability and ability all perform strong correlation, and the correlation of ability has a slightly better rate than vulnerability; When the system overtakes the threshold value, vulnerability is significantly related, and now the correlation strength between ability and public security level remains at the medium level.

\section{References}

[1] Alwang J, Siegel PB, Jorgensen SL. Vulnerability: A View from Different Disciplines[R]. Discussion Paper Series No. 0115. Social Protection Unit, World Bank, Washington DC. 2001

[2] Luers AL. The surface of vulnerability: an analytical framework for examining environmental change [J]. Global Environmental Change, 2005, 13(4): 214-223.

[3] Engels. Natural dialectics [M].Beijing: People's Publishing house.1971, 49. (In Chinese)

[4] Thom R. Structural Stability, Catastrophe Theory, and Applied Mathematics: The John von Neumann [J]. SIAM Review, 1977, 19(2): 189-201.

[5] Niemeyer S, Petts J, Hobson K. Rapid climate change and society: Assessing responses and thresholds [J]. Risk Analysis, 2005, 25(6): 1443-1456.

[6] Lagi M, Bertrand KZ, Bar-Yam Y. The Food Crisis and Political Instability in North Africa and the Middle East [Z]. http://necsi.edu/research/social/food_cris es.pdf, 2011:1-15.

[7] United Nations Development Programme (UNDP). Disaster Risk Index (DRI) Analysis Tool [EB/OL]. http://gridca.grid.unep.ch, [2005-04-10].

[8] Federal Emergency Management Agency (FEMA). FEMA/DHS Office of National Security Coordination Continuity of Operations (COOP) Assessment Questionnaire/Worksheet [Z]. Washington DC: FEMA, 2004: 1- 14.

[9] National University of Colombia-Manizales, Inter-American Development Bank. System of Indicators for Disaster Risk Management: Program for Latin America and the Caribbean Main Technical Report [EB/OL]. http://idea.unalmzl.edu.co, 2005-08-01.
[10] ZHU Z.W., CAI Li, DUAN D.. Framework of social security assessment based on the "vulnerability-ability" perspective $[\mathrm{J}]$. China's Public Administration, 2011(8), 101-106. (In Chinese)

[11] UN/ISDR. Living with risk: A global review of disaster reduction initiatives[R]. United Nations publication: Geneva. 2004.

[12] Yohea G., Tolb R. Indicators for social and economic coping capacity - moving toward a working definition of adaptive capacity [J]. Global Environmental Change, 2002, 12(1): 25-40. 